\title{
HET EXPERIMENTEEL BEINVLOEDEN VAN HET VERLOOP DER GENERATIES BIJ DE COLORADOKEVER (LEPTINOTARSA DECEMLINEATA SAY)*
}

DOOR

DR J. DE WILDE

\section{INLEIDING}

De ontwikkeling van de coloradokever van ei tot imago neemt 25 à 60 dagen in beslag, afhankelijk van het klimaat in het gebied waar de ontwikkeling plaats heeft. Trouvelot (1936) onderscheidt in het Noord-Amerikaanse verspreidingsgebied 5 klimaatszônes; in de Zuidelijkste hiervan duurt de ontwikkeling. van een cyclus 25 à 30 dagen, in de Noord-Oostelijke 50 à 60 dagen.

Ook in West-Europa zijn aan de ontwikkelingsduur overeenkomstige limieten gesteld; de sterk variabele temperatuur bemoeilijkt hier echter het vaststellen van zônes als de Amerikaanse. Men zou nu verwachten, dat in gebieden met een snelle ontwikkeling het aantal generaties per seizoen groter zou zijn, dan in zulke met trage ontwikkeling. Wanneer men de literatuur hierover raadpleegt, ontmoet men tegenstrijdige gegevens. Tower (1906) beschrijft in zijn beroemde monografie de ,habits and instincts connected with hibernation and aestivat:on" en deelt mee, dat in Tuckson (Arizona) imagines van de eerste generatie tot eiafzetting overgaan. Die van de tweede generatie zouden echter geen voortplantingsactiviteit vertonen, tenzij na een periode van overwintering of aestivatie.

Andere onderzoekers hebben dit tegengesproken. Girault verrichtte kweekproeven in Ohio (1908), Georgia (I907) en Illinois (I909) en constateerde, dat de tweede generatie wel degelijk tot eiafzetting in staat is. De kweekproeven werden slechts met enkele paren kevers uitgevoerd, zodat niet is uit te maken of dit verschijnsel regel was of uitzondering; veldwaarnemingen zouden volgens Girault op het eerste wijzen.

FINK (1925), die waarnemingen deed in de omgeving van Philadelphia, constateerde in kweekproeven, dat steeds de jonge kever kort na het ontpoppen de neiging heeft in overwintering te gaan. Er zou zich dus slechts één generatie per jaar ontwikkelen. Deze voorbeelden mogen voldoende zijn om aan te tonen

*) Onderzoek, uitgevoerd in dienst van het Ministerie van Landbouw, Visserij en Voedselvoorziening. 
hoe gering ruim 75 jaar na het begin der coloradokeverinvasie in NoordAmerika onze kennis nog was omtrent het aantal generaties en de aantalsverhouding hiervan, die toch zo nauw samenhangt met het verloop van de aantasting en dus met de schade. Tot omstreeks 1940 was men ook in Europa hieromtrent nog merkwaandig slecht ingelicht.

De Franse onderzoekers uit de school van Trouvelot hebben echter de laatste jaren veel opheldering verschaft. Vooral Grison en Boczkowska hebben in dit opzicht belangrijk werk verricht.

Grison (1938) vermeldt, dat in het district Creuse (Midden-Frankrijk) de volwassen kevers van de eerste generatie voor het merendeel kort na de ontpopping de grond ingaan; in de regel ontwikkelt zich slechts één generatie per jaar. Hetzelfde zou gelden voor de omgeving van Parijs en Bretagne.

In sommige delen van Zuid-Frankrijk zou volgens BoczkowsKA (o.a. 1944) de tweede generatie talrijker zijn en de door deze generatie veroorzaakte schade dienovereenkomstig belangrijker dan in Midden- en Noord-Frankrijk. In Nederland tenslotte hebben wij tijdens drie jaar onderzoek kunnen constateren, dat alleen gedurende extreem warme zomers (bv. die van 1947) de eerste generatie voor een deel tot eiafzetting overgaat, maar ook dan slechts voor korte tijd en voor een gering percentage. In 1946 en I948 ontwikkelde zich slechts een onbetekenende tweede generatie, hoewel de temperatuur in Juli en Augustus in beide jaren de larvale ontwikkeling toeliet. We zien hieruit van hoe grote betekenis het vroege intreden van de rusttoestand is voor het verloop van de ontwikkeling der keverpopulatie in ieder seizoen. Doel van de in dit artikel vermelde proeven is, een bijdrage te leveren tot de kennis van de factoren, die het intreden en het verbreken van deze imaginale rusttoestand bepalen.

\section{AARD VAN DE IMAGINALE RUSTTOESTAND}

Overwintering en aestivatie zijn bij de co'oradokever niet scherp gescheiden; dikwijls vertonen reeds in Juli de eerste volwassen kevers de neiging zich in de grond te begeven. Deze dieren hervatten hun activiteit eerst weer het volgend voorjaar; zij aestiveren dus eerst en overwinteren daarna. De overwintering in de grond geschiedt op een diepte van 25 à $50 \mathrm{~cm}$.

Wanneer we het gedrag van de imagines van verschillende generaties nagaan, blijkt het volgende: de imagines, die in het voorafgaande jaar geboren zijn (generatie nul), verschijnen in het voorjaar, zodra de grondtemperatuur op de plaats van overwintering 5 à $10^{\circ} \mathrm{C}$ bedraagt (TROUVELOT, BRENY, eigen waarnemingen). De meeste overwinterende wijfjes zijn bevrucht. Zodra de aardappelplant zich gaat ontwikkelen en de temperatuur voldoende is gestegen, begint de eiafzetting, die tot in Juli voortduurt. Daarna vermindert ze en in Augustus, September en October gaat een deel van de dieren tot overwintering over.

De eerste imagines van de eerste generatie verschijnen gewoonlijk in de loop 
van Juli; hierna neemt het aantal geleidelijk toe. Twee à vier weken na de ontpopping begeeft zich het merendeel van de kevers in de grond. Een gering percentage van de vroegst verschenen dieren gaat tot eiafzetting over, doch met geringe intensiteit. Dieren, die in einde Juli en Augustus verschijnen, zetten gewoonlijk in het geheel geen eieren meer af. Grafiek I geeft een beeld van het verloop van verschijning en ingraven van kevers behorende tot de eerste generatie 1945 en 1946 in kweekproeven in buitenkooien, genomen in het jaar I946. In de koele zomer van 1946 verscheen de eerste generatie in

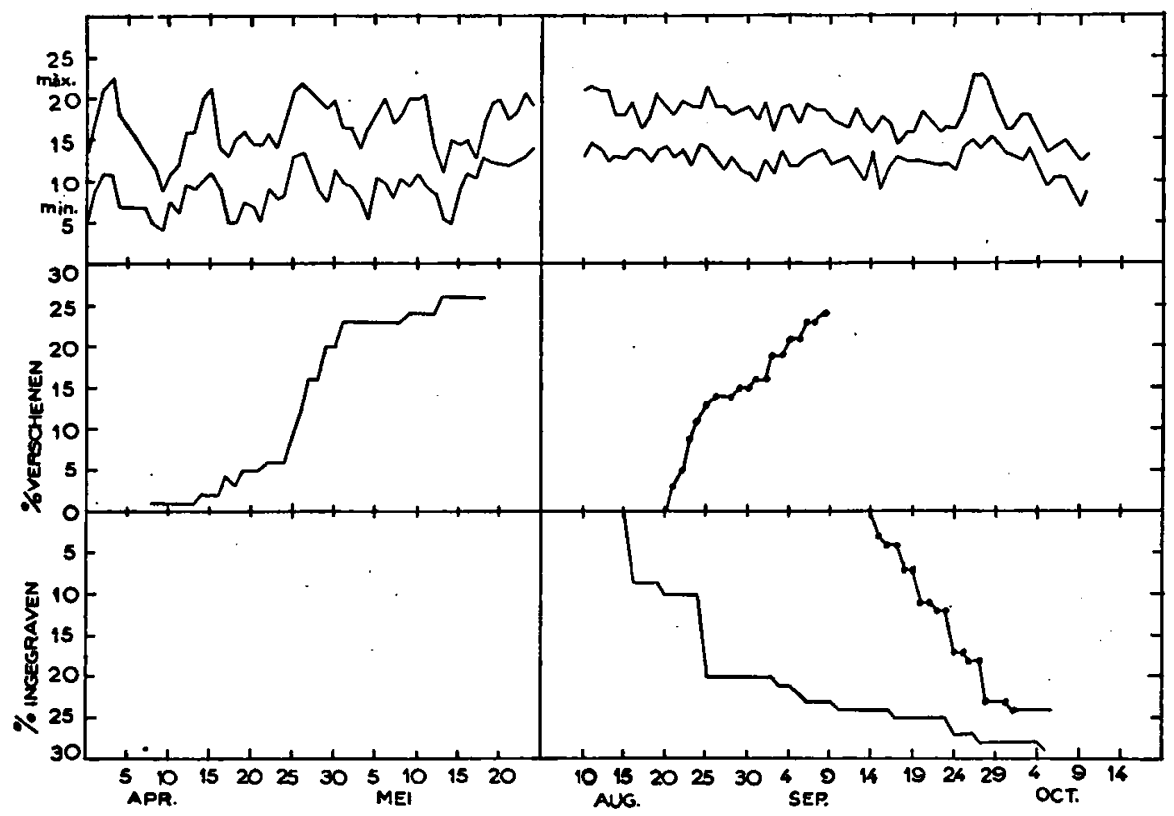

Fig. I. Verloop van verschijning en ingraven van de volwassen kevers van generatie o (eerste generatie 1945, getrokken lijn) en generatie I (stippellijn) in 1946. Men merke op dat de temperatuur eerst na afloop van het ingraven der eerste generatie begon te dalen. De gegevens hebben betrekking op kweken in buiten-insectaria. De temperatuur werd ter plaatse geregistreerd.

onze kooien bijna een maand later dan in 1947 en omgekeerd ging generatie o ongeveer een maand vroeger in diapause. De gestippelde curven lagen dus in I947 tussen de getrokken curven.

Uit deze en andere waarnemingen kregen wij de indruk, dat het vroegtijdig ingraven van de eerste generatie niet door lage temperatuur en ongunstige voedselcondities kon worden veroorzaakt. Ook in Frankrijk is men deze mening toegedaan. GRISON (I946) beschouwt de rusttoestand van de eerste generatie als een echte diapause (sensu Roubaud, 1922). Deze zou aangeboren zijn en deel uitmaken van de ontwikkelingscyclus.

De diapause wordt voorafgegaan door een periode van intensieve voedselopname en vetafzetting. Deze inleidende fase wordt praediapause genoemd.

Bijdragen tot de Dierkunde, Afil. 28. 


\section{WIJZIGING VAN DE DUUR DER PRAEDIAPAUSE EN HET PERCENTAGE DIAPAUSEDIEREN DOOR MILIEUFACTOREN}

In 1946 en 1947 waren wij in de gelegenheid proeven te nemen in de constante kamer van de Hortus Botanicus ${ }^{1}$ ) te Amsterdam, waarbij getracht werd, door het kiezen van zo gunstig mogelijke omstandigheden de ovipositie te bevonderen. Hiertoe werden kevers direct na de ontpopping in een insectarium

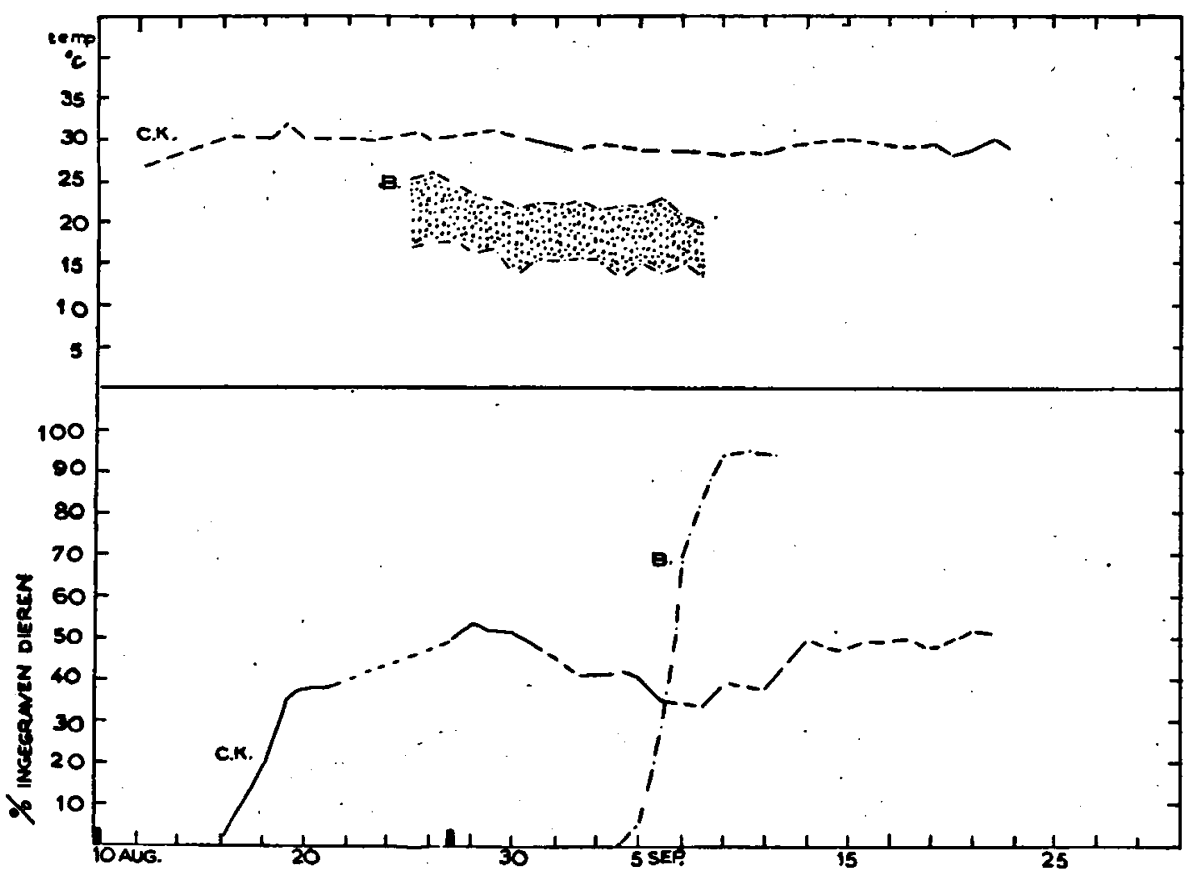

Fig. 2. Verloop van de temperatuur en het ingraven van de imagines der eerste generatie 1947 in een constantie kamer (C.K.) bij continue belichting à \pm 3750 Lux, resp. in buiten-insectaria (B) te Amsterdam. Voedering in beide gevallen met jong loof van var. Eerstelingen. De zwarte blokjes op de abscis geven het tijdstip van ontpopping (begin der voedering) aan.

voortgekweekt bij constante temperatuur en permanente belichting van hoge intensiteit. Deze wend verkregen door een loodrecht naar beneden stralende lichtbron van 7 met water gekoelde lampen à 500 W., geplaatst in een bak met glazen bodem. Onder deze lichtbron werd een insectarium met glazen dak geplaatst, dat voorzien was van een laag tuinaarde. In het insectarium was een verticale gazen scheidingswand aangebracht. In ieder der beide vakken werd een flesje met aardappelloof geplaatst, dat dagelijks werd ververst. De lichtsterkte aan de oppervlakte van het loof bedroeg gemiddeld 3750 Lux. De relatieve luchtvochtigheid bedroeg $65-80 \%$. Dagelijks werd het aantal bovengrondse dieren en het aantal eieren vastgesteld.

I) Prof. Dr. A. W. H. vax Herk danken wij ten zeerste voor de genoten gastvrijheid. 
In 1946 werden oriënterende proeven genomen, waarbij bleek dat de ouderdom van het gevoederde aardappelloof geen belangrijke invloed had op de diapause. Van 24 proefdieren stierven er vijf, terwijl 9, dus ongeveer de helft van de overlevende dieren in diapause gingen. De temperatuur bedroeg 23 à $24^{\circ} \mathrm{C}$.

In 1947 werd de proef herhaald, thans met $5^{\circ}$ imagines. De temperatuur

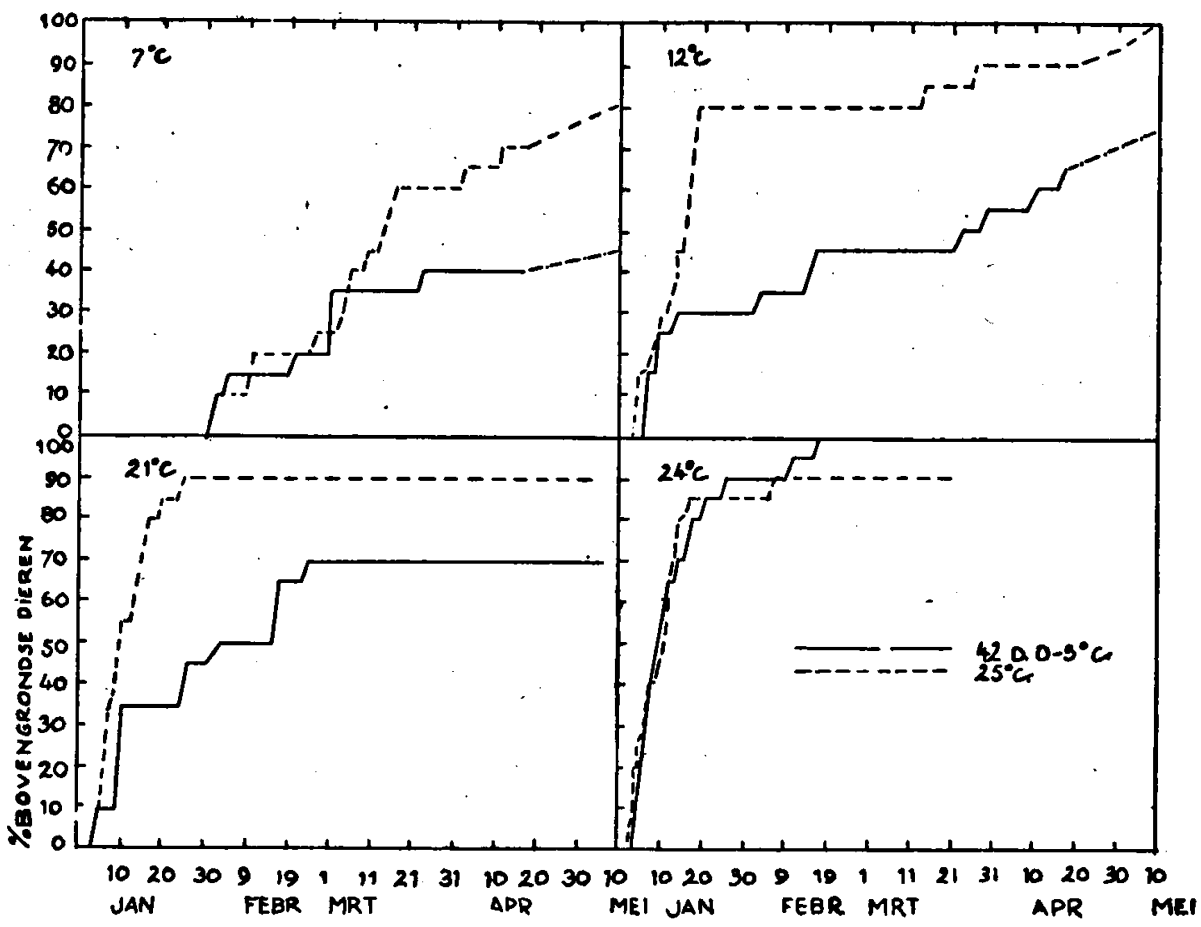

Fig. 3. Verloop van het boven de grond verschijnen van gekoelde (- - ) en bij $25^{\circ}$ C. bewaarde (----) kevers van de overwinterende generatie in 1948, na plaatsing bij verschillende (constante) temperaturen. Iedere proef omvatte 20 individuen. De koeling werd. 2 Januari beëindigd. Afkoeling vertraagt het verbreken der diapause.

bedroeg $29^{\circ} \mathrm{C}$, vochtigheid en belichting als in de vorige proef. Ook in dit geval ging ongeveer $50 \%$ van de dieren in diapause.

Omstreeks de zelfde tijd werd een 20-tal imagines in de tuin van het entomologisch laboratorium, direct na de ontpopping in een buiteninsectarium opgekweekt; alleen belichting en temperatuur verschilden belangrijk van die in de constante kamer. De vochtigheid was slechts weinig lager, het voedsel gelijk.

Het verloop van het ingraven van de dieren in beide gevallen wordt in figuur 2 weergegeven. In de buitenkooi begaven zich alle dieren in de grond.

Merkwaardig was de invloed van de temperatuur op de praediapause. Deze laatste verliep in de constante kamer ongeveer twee maal zo snel als in de 
buitenkweek. Van de dieren, die bovengronds bleven, gingen de wijfjes alle in ovipositie. De eiafzetting werd gedurende $3^{6}$ dagen nagegaan en bedroeg 27 eieren per wijfje per dag.

\section{INVLOED VAN LAGE TEMPERATUREN OP HET BEEINDIGEN VAN DE DIAPAUSE}

Embryonale en pupale diapause kunnen bij insecten door verblijf bij lage temperatuur worden verbroken. Hiervoor is nodig een verblijf van enige weken bij een temperatuur beneden de ontwikkelingsdrempel; temperaturen beneden het vriespunt zijn niet noodzakelijk.

In de winter $1947 / /^{\prime} 48$ hebben wij nagegaan, of hetzelfde geldt voor de imaginale diapause van de coloradokever. Hiertoe werd een roo-tal imagines, die in diapausetoestand bij $25^{\circ} \mathrm{C}$ in het laboratorium waren bewaard vanaf 2I November gedurende 42 dagen in een ijskast bij $0-5^{\circ} \mathrm{C}$ gekoeld. Een gelijk aantal dieren werd bij $25^{\circ} \mathrm{C}$ verder bewaard. $\mathrm{Na}$ afloop van de koeling werd elk der partijen verdeeld in groepen van 20 stuks, die in bakjes aarde in 5 vakken van een seriethermostaat werden geplaatst. De temperatuur bedroeg hierin resp. 7, I2, I7, 21 en $24^{\circ} \mathrm{C}$. Dagelijks werd de aarde op een gunstig vochtigheidspeil gehouden en het aantal boven de grond verschenen dieren geteld. Figuur 3 geeft het resultaat weer. Hieruit blijkt, dat de niet gekoelde dieren eerder verschenen dan de gekoelde. De verschillen waren, zoals te verwachten was, geringer naarmate de temperatuur hoger was.

\section{CONCLUSIE}

Onze proeven vormen een bevestiging van de opvatting van Grison, dat de coloradokever een imaginale diapause bezit, die in de ontwikkelingscyclus direct na de ontpopping is ingeschakeld.

Gunstige temperatuur en belichting kunnen bij een deel der imagines de diapause onderdrukken ten gunste van de voortplanting. Dit gelukte bij 24 resp. $29^{\circ} \mathrm{C}$ en continue belichting van gemiddeld 3750 Lux bij ongeveer $50 \%$ der individuen. Temperatuurstijging versnelt de praediapause.

De diapause draagt een ander karakter dan de pupale diapause der Lepidoptera. Verblijf bij lage temperatuur vertraagt nl. het verbreken der diapause, terwijl bij Lepidopterenpoppen het verbreken aanzienlijk wordt versneld.

De conclusie is dus gewettigd, dat bij de coloradokever de processen, die het verbreken van de diapause ten gevolge hebben, gedurende de diapause niet stilstaan, doch worden voortgezet.

\section{SOMMAIRE}

Etude expérimentale de la succession des générations chez le Doryphore (Leptinotarsa decemlineata Say).

On a confirmé la presence d'une diapause vraie dans le cycle évolutif du 
Doryphore, diapause qui commence peu de temps après la mue imaginale. On peut, par une température et éclairage favorable, supprimer cette diapause en faveur de la réproduction. A $25^{-29^{\circ}}$ C. et éclairage continue de $375^{\circ} \mathrm{Lux}$, la suppression de la diapause a réussi pour $50 \%$ des individus. La diapause est accélérée quand la température monte; la durée de la praediapause est doublée quand la température s'abaisse de $29^{\circ} \mathrm{C}$ à $15^{-25^{\circ}} \mathrm{C}$.

La diapause imaginale du Doryphore diffère de la diapause nymphale des Lepidoptères en ce qui concerne l'influence d'une periode de froid. Une telle periode de 42 jours à $0-5^{\circ} \mathrm{C}$ ralentie la rupture de la diapause du Doryphore, ce qui montre que les processus qui finirent par la rupture de la diapause ne sont pas arrêtés en hiver mais sont prolongés graduellement.

\section{LITERATUUR}

Boczkowska, M., 1944. C. R. Ac. Agr. Fr.

BrenY, R., I94I. Bull. Inst. Agr. Stat. Rech. Gembloux, 147-15I.

Fink, D. E., 1925. Biol. Bull. 49, p. 381-406.

Girault, A., 1907. Psyche 14, p. 45-47.

-, 1908. Ann. Ent. Soc. Amer. I, p. 155-178.

1909. Ann. Ent. Soc. Amer, 2, p. 71-83.

GrIson, P., 1938. Abh. VII Int. Kongr. Ent.

一, 1944. C. R. Ac. Sci. 218, p. 342-344.

Roubaud, E., 1922. Bull. Biol. Fr. Belg. 56, p. 455-544

TOWER, W. L., Igo6. Publ. Carnegie Inst. Washington.

Trouvelot, B., 1936. Bull. Inst. Agr. Stat. Rech. Gembloux. 